\title{
English Oral Communication Needs of Bhutanese Students: As Perceived by the Teachers and Students
}

\author{
Singay ${ }^{1}$ \\ ${ }^{1}$ TESOL Department, Payap University, Chiangmai, Thialand \\ Correspondence: Singay, TESOL Department, Payap University, Chiangmai, Thialand. Tel: 66-097-838-061. \\ E-mail: singay6@gmail.com
}

Received: January 4, 2018

Accepted: March 15, 2018 Online Published: March 18, 2018

doi: $10.5539 /$ elt.v1 $1 \mathrm{n} 4 \mathrm{p} 74$

URL: http://doi.org/10.5539/elt.v11n4p74

\begin{abstract}
The main aim of this study was to investigate the oral communication needs in English from the perspective of students and teachers to improve students' oral communication ability. A questionnaire was administered to 45 participants consisted of 36 students and 9 teachers. The data were analyzed using descriptive statistics like mean and standard deviation. Results revealed that students and teachers had different standpoints of oral communication needs in English in the classroom, especially with regard to general listening and speaking skills. In addition, findings from the questionnaire suggested that teachers and students perceive speaking and listening informally in situations, for instance working in pair, discussion in small groups, role plays, interviews, classroom debates, storytelling, and being able to communicate orally with teachers as most important oral communication abilities to be practice in the classroom. Lastly, the most important oral communication abilities such as the use of academic language in the classroom and daily conversation in English should also be taken into account to ensure effective oral communication in the classroom.
\end{abstract}

Keywords: need analysis, oral communication, students' needs, teachers' needs

\section{Introduction}

Modern education was instituted in Bhutan in early 1960's to carry out country's first social, economic, jurisdictional and political reforms; and to communicate successfully with the global world. The introduction of Western education was crucial to build a group of qualified and experienced people who were knowledgeable enough to do the job. Thus, English was introduced as a means of instruction and official communication language in Bhutan. Since then, the use of English has grown speedily due to its stature and impact as a global language - "the language of science, technology, commerce and international relations" (CAPSD, 2006b). The Government of Bhutan considered English as a language of benefit for Bhutanese in the globalized world because it could help Bhutan in articulating its identity (CAPSD, 2006a) and help people to participate in the global community productively. Presently, English is recognized as Bhutan's "language of international relations and modernization" (DDC, 2002).

Though English has been used as a medium of instruction in Bhutan for more than 50 years, the majority of Bhutanese students' still face difficulties in speaking English fluently and to develop oral communication ability for daily conversation. A study of student achievement in English and Mathematics literacy in class ten by Bhutan council of school examination and assessment BCSEA (2013) shows that "almost an equal number of these students faced difficulties in speaking and writing skills compared to listening and reading" (p. 39). There are many problems hindering the development of learners' oral communication ability. Firstly, it is due to lack of importance placed on oral fluency or communicative competence. Secondly, it is attributed by lack of opportunities to practice oral communication in the classroom. Lastly, due to the result of fidelity to obsolete teaching methods and the lack of attention on the importance of supporting oral language proficiency in all subject areas.

The English curriculum in Bhutan consists of the four modes of discourse; reading and literature, writing, listening and speaking, and language and grammar. Among four modes of discourse, oral communication (listening and speaking) seems to be neglected skills by the teachers in the language classroom due to lack of testing objective for students' oral proficiency in the examination. LaPrairire (2014) stated that the exclusion of oral proficiency as part of the exams in Bhutan decreases the importance of speaking as a language skill to be 
mastered and an essential part of language learning. Similarly, English language teachers in Bhutan reported that they normally do not rate the language as part of the examination, but focused solely on whether students can demonstrate an acceptable knowledge of subject content independently, irrespective of language use (LaPrairire, 2014).

In many Bhutanese classrooms, particularly at middle or high schools. Students are not offered ample opportunities to practice oral communication skills; thus, students have limited use of authentic language. According to LaPrairire (2014), many young Bhutanese who had completed the full cycle of secondary education, still cannot make or engage in a simple conversation in English. This clearly indicates that students are not motivated to engage orally in classrooms, where oral communication and classroom interaction does not focus on the skills that are learned and used. If these skills are practiced in school, it will bestow them the skill to engage in conversations and common discourse in English.

Lastly, Wu and Ling (2007) point out the causes of psychological barriers in teaching and found that language teaching modes and methods are one of the main factors that obstruct learner's oral communication ability and proficiency. Most of the classroom practices in Bhutan are characterized by teachers' talks, comments, and students remaining passive. Thus, students cannot use English as an effective tool to think critically, give reason, solve problems and interact socially. Consequently, the use of oral communication in the classroom is limited and students are not provided opportunities to practice oral communication in the classroom. LaPrairire (2014) stated that students at different levels of the school and university cannot use English as an effective tool for classroom discussion, asking questions and raise issues, generate new ideas or challenge existing ones, express opinions, analyze and interpret data.

The current needs analysis is to investigate the English language needs and perception in terms of oral communication abilities important for students at the high school level. With the aim of developing language program especially for developing oral communication ability for ESL students in Bhutan, a survey study was conducted with teachers and students to answer the following research questions:

1). What are some of the oral communication abilities perceived important by the teachers and students?

2). Which oral communications abilities are consider more significant by each group of participants compare to other group?

\section{Literature Review}

\subsection{Needs Analysis}

Brown (1995) define needs analysis as "the systematic collection and analysis of all subjective and objective information necessary to define and validate defensible curriculum purposes that satisfy the language learning requirements of students within the context of particular institutions that influence the learning and teaching situation" (p. 36). The end result of a needs analysis should be used to frame list of goals and objectives for the individuals involved in designing syllabus. Which should "serve as the basis for developing tests, materials, teaching activities, and evaluation strategies, as well as for reevaluating the precision accuracy of the original needs assessment" (Brown, 1995, p. 35).

Needs analysis plays an indispensable role during the stages of developing and conducting language courses and study programs. The term needs refer to wishes, desires, expectations, demands, motivation, shortcomings, constraints, and requirements (Brindley, 1989), or it is defined as the necessary language skills and language forms that students will probably need to use on target language to communicate effectively in a foreign language context. Other approaches to the term define needs as (a) what students need to learn; (b) how they feel about learning; (c) how much effort they can invest and (d) how much capacity they have for the learning process (Manolopoulou-Sergi, 2004).

The purpose of the needs analysis is to enable teachers and curriculum designers to interpret students' language and instructional needs in order to teach an effective course (Mackey, 1978). Numerous researchers (Richards 2012, Tarone and Yule 1989) sees the importance of needs analysis in language courses because when they conduct needs analysis, students actively participate in their learning and they are also included in decision making regarding their needs and wants. Richards (2012) accentuates that successful teaching requires taking into account factors such as knowledge, views of learning, learning styles and motivation. In addition, the needs analysis is the specification of the language needs of the students before and during the implementation of the curriculum or course (Fatihi, 2003, Watanabe, 2006). 


\subsection{Oral Communication}

The communication can be oral and written. Written communication is an exchange of ideas through the written medium, while oral communication is the oral interaction between two or more people. By its very nature, spoken language involves at least two immediate participants, a speaker and a listener.

Oral communication is the art of expressing and exchanging ideas with words. It is the ability to analyze critically, present ideas, compose, and provide information through verbal and non-verbal interactions. Presentation skills, public awareness, critical listening and body language are some of the basic requirements of oral communication.

Oral communication is a bidirectional process between speakers and listeners and involves the ability to speak and understand. The speaker has to encode the message he/she wishes to convey in an appropriate language, while the listener is helped by prosodic features such as stress, intonation, facial expressions, body movements and gestures (Bygate, 1987). Oral communication is a unique and learned oratorical skill that requires understanding what to say and how to say it.

Therefore, oral communication skills are a set of skills that allow people to be confident and competent communicators. They give students the opportunity to understand, criticize and analyze information efficiently and communicate clearly.

\section{Method}

\subsection{Research Design}

The quantitative research approach was used in this study. The researcher used purposive sampling to identify the needs of students and teachers to develop students' oral communication ability. The current study uses methods that describe, and analyze the needs of learners and teachers for enhancing oral communication ability.

\subsection{Population and Sample of the Study}

The sample population in this study consisted of teachers and students. They were chosen purposively. The participants were 36 students and 9 teachers.

\subsection{The Instruments of the Study}

There are two sets of questionnaires developed for teachers and students. The second part of the teacher questionnaire and third part of the student questionnaire were adapted from Ferris and Tagg (1996a). The second part of student questionnaire was adapted from Iwai et al. (1999). The aim of these questionnaires was to gather information on the importance of oral communication skills for enhancing oral communication ability from the view point of teachers and students.

\subsubsection{Teacher Questionnaire}

The teacher's questionnaire consisted of two sections. The first section contained personal information that asked for relevant information about their age and sex, current teaching level, and the number of teaching experience in Bhutanese classroom. The next section comprised of fourteen questions on a four-point Likert scale, which presents skills or items and asked teachers to assess the degree of importance. The four points on the Likert scale were categorized as very important, important, somewhat important, and not very important.

\subsubsection{Student Questionnaire}

The student's questionnaire consisted of three sections. The first section included personal information that asked for relevant information about their gender, age, and difficulties among four language skills. The second section included 16 items on four-point Likert Scale and asked students to rate the extent to which they agree or disagree with responses from the items. The last part of questionnaire asked students to rate all skills in order of their importance and it was similar with that of second part of teacher questionnaire.

\subsection{Data Collection}

The questionnaires were distributed to the target participants (students and teachers) in Bhutan from October to November 2017 for the period of two months. Data collection was carried out by the researcher himself with the help of few colleagues.

\subsection{Data Analysis}

After the questionnaires were collected, the data were described and analyzed using the Statistical Package (SPSS) program version 20. Then the data were presented and explained in a descriptive table by using mean and standard deviation. 


\subsection{Validity and Reliability}

Importantly, before collecting data, teacher and student questionnaire was trailed. The questionnaire was sent to a group of two ELT experts with similar backgrounds to read the student and teacher questionnaire and they provided comments on the language and content of the questionnaire. This process assisted in clarify the confusing language, resulting in the suppression of redundant elements and to ensure that the questions or items in the questionnaire were appropriate to measure the research objectives and to ensure that the content was understandable to the students.

The teacher and student questionnaire contained different items on four Likert scales ranging from "very important" to "not very important". The Cronbach's Alpha coefficient was used in this study to evaluate the reliability of the questionnaire. The result of the reliability test for the students' questionnaires was found as $\alpha$ $=.887$, and for the teachers $\alpha=.756$.

\section{Results}

4.1 What Are Some of the Oral Communication Abilities Perceived Important by the Teachers and Students?

(a) Oral communication abilities perceived as important by the teachers

Table 1 shows the results of the response of 9 teachers. The table was organized in a column to show the numbers of the items with the mean (M) and the standard deviation (SD). In brief, the items or abilities that teachers considered most important have a very high mean, while the items that teachers considered to be least important have a very low mean. The higher values for the standard deviation indicate a greater variation in the responses among the teachers. Table 1 shows that the teachers perceived item 3 listening comprehension (M: 2.33, SD: .707) followed by item 8 requesting or receiving information in person (M: 2:22, SD: .667), item 2 lecture note taking (M: 2.11, SD: 1.054), item 7 interviewing or being interviewed (M: 2.00, SD: .707), and item 11 conducting or participating in the meeting (M: 2.00, SD: .707) as an important oral communication abilities. On the other hand, teacher perceived Item 4, 5, 6 and 12 (M: 1.56, SD: .527) as least important oral communication abilities to be practice in the classroom.

Table 1. Results from teachers' questionnaire in question order

\begin{tabular}{lll}
\hline Items & Mean & SD \\
\hline 1. Pronunciation/intonation/stress & 1.78 & 1.093 \\
2. Note taking (lecture) & 2.11 & 1.054 \\
3. Listening comprehension (besides formal lectures) & 2.33 & .707 \\
4. Ability to deliver formal speeches/presentations & 1.56 & .527 \\
5. Ability to communicate orally with peers in the group discussion, collaborative & 1.56 & .527 \\
projects or out of class study groups & 1.56 & .726 \\
6. Ability to communicate orally with teachers inside and out of the class. & 2.00 & .707 \\
7. Interviewing or being interviewed & 2.22 & .667 \\
8. Requesting or receiving information in person. & 1.78 & .833 \\
9. Classroom discussion on issue or situations & 1.89 & .601 \\
10. Formal speaking and responding as part of an audience & 2.00 & .707 \\
11. Conducting or participating in the meeting & 1.56 & .726 \\
12. Presenting or listening to oral reports or seminars & & \\
\hline
\end{tabular}

(b) Oral communication abilities perceived as important by the students

Table 2 shows the results of the 36 students. The table was organized similarly with that of table 1 to show the item number with the mean (M) and the standard deviation (SD). The table was structured in mean order, whereby, the questions were ordered in such a way that the questions with the highest mean (most important) are at the top and those with the lowest average (least important) are at the bottom. The table was structured in that way to show, which skills were most preferred by the students. As shown in the below table, the five most important oral communication abilities perceived essential by the students are; item 12 to socialize with my 
friends (e.g., planning parties/picnics, phone conversations (M: 2.31, SD: .980), followed by item 15 travel to an English speaking country (E.g. take a taxi, eat at restaurants) (M: 2.25, SD: .906), item 16 talk to foreigners and tourists who visited foreign countries (e.g. give directions) (M: 2.03, SD: 1.028), item 6 engage in formal interviews (e.g., scholarship/job interview) (M:1.89, SD:.950), and finally, item 3 engage in classroom discussion on current events and social issues (M:1.78, SD:.637), respectively. In contrast, deal with in-class routines in English (e.g., greeting, asking questions, following the teacher's directions) discussions was reported as the lowest skills being used by the students.

Table 2. Results from teachers' questionnaire (Mean Order)

\begin{tabular}{|c|c|c|}
\hline Items & Mean & SD \\
\hline SECTION II & \multirow{2}{*}{2.31} & \multirow{2}{*}{.980} \\
\hline 12. Socialize with my friends (e.g., planning parties/picnics, phone conversations & & \\
\hline 15. Travel to an English-speaking country (e.g. take a taxi, eat at restaurants) & 2.25 & .906 \\
\hline 16. Talk to foreigners and tourists who visited foreign countries (e.g. give directions) & 2.03 & 1.028 \\
\hline 6. Engage in formal interviews (e.g., scholarship/job interview) & 1.89 & .950 \\
\hline 3. Engage in classroom discussion on current events and social issues & 1.78 & .637 \\
\hline $\begin{array}{l}\text { 5. Consult with my teacher in English (e.g., asking permission to be absent from a class, } \\
\text { discussing class-related material) }\end{array}$ & 1.69 & .786 \\
\hline $\begin{array}{l}\text { 14. Understand English for entertainment (e.g., watching TV programs/videos, reading } \\
\text { comic books, magazines, novels }\end{array}$ & 1.67 & .632 \\
\hline $\begin{array}{l}\text { 11. Help non-English speaking family or friends (e.g., filling out forms, giving directions, } \\
\text { checking in, making reservations, scheduling, trouble-shooting) }\end{array}$ & 1.61 & .688 \\
\hline 4. Engage in classroom discussions (e.g., cultural differences, personal stories) & 1.58 & .874 \\
\hline 10. Use English fluently (e.g., appropriately, with other people, in the right situation) & 1.56 & 607 \\
\hline $\begin{array}{l}\text { 2. Give in-class presentations/demonstrations in English (e.g., reporting in class on how to } \\
\text { make/use something) }\end{array}$ & 1.53 & .506 \\
\hline 7. Understand academic/technical English terms relevant to subjects (e.g. math, science) & 1.50 & .561 \\
\hline 9. Use English accurately (e.g., correct grammar, punctuation) & 1.44 & .652 \\
\hline $\begin{array}{l}\text { 1. Deal with in-class routines in English (e.g., greeting, asking questions, following the } \\
\text { teacher's directions) }\end{array}$ & 1.42 & .500 \\
\hline
\end{tabular}

According to Table 3, the five most important oral communication abilities from Section three to enhance oral communication ability by the students are; item 25 requesting or receiving information in person (M:2.06, SD:.893), followed by item 24 interviewing or being interviewed (M:1.78,SD:.866), item 26 classroom discussion an issue or situation (M1.75, SD:.806), item 21 ability to communicate orally with peers in small group discussion, collaborative project, or out of class study group (M:1.75,SD:.732) and item 18 lecture note taking (M:1.75,SD:.806), respectively. In contrast, ability to give formal speeches/presentations ability to participate effectively in class discussions was reported as the lowest skills being used.

Table 3. Results from students' Questionnaire (Mean Order)

\begin{tabular}{lcc}
\hline Items & Mean & SD \\
\hline SECTION III & 2.06 & .893 \\
25. Requesting or receiving information in person & 1.78 & .866 \\
24. Interviewing or being interviewed & 1.75 & .806 \\
26.Classroom discussion on issue or situation & 1.75 & .732 \\
21. Ability to communicate orally with peers in small group discussion, collaborative & \\
\hline
\end{tabular}


project, or out of class study group

18. Note taking (lecture)

$1.75 \quad .806$

19. Listening comprehension (besides formal lectures)

$1.72 \quad .615$

29. Presenting or listening to oral reports or seminars

$1.69 \quad .710$

28.Conducting or participating in a meeting

$1.64 \quad .762$

27. Formal speaking and responding as part of an audience

$1.61 \quad .599$

21.Ability to communicate orally with teachers in or out of class

$1.53 \quad .609$

17. Pronunciation/intonation/stress

$1.44 \quad .773$

20. Ability to deliver formal speeches/presentations

$1.14 \quad .351$

\subsection{Which Oral Communications Abilities Are Consider More Significant by Each Group of Participants Compare to Other Group?}

Table 4 compares the mean scores of teachers and students on those items which had same importance. The items in the table appears are as they were in the questionnaire. As per the table 4, students perceived; item 8 requesting or receiving information in person (M: 2.06, SD: .893) as most important abilities followed by item 7 Interviewing or being interviewed (M: 1.78, SD: .866), while teachers ranked items 3, listening comprehension (M: 2.33, SD: .707) as most important followed by item 8 requesting or receiving information in person (M: 2.22, SD: .667), respectively. In contrast, students ranked item 4 ability to deliver formal speeches/presentations, whereas teachers ranked item 4,5 and 12 were lowest skills to be practiced in the class.

Table 4. Oral communication abilities perceived important by teachers and students

\begin{tabular}{lllll}
\hline Items & \multicolumn{2}{c}{ Students(36) } & \multicolumn{2}{c}{ Teachers(9) } \\
\hline 1. Pronunciation/intonation/stress & 1.44 & .773 & 1.78 & 1.093 \\
2. Note taking ( Lecture) & 1.75 & .806 & 2.11 & 1.054 \\
3. Listening comprehension( General) & 1.72 & .615 & 2.33 & .707 \\
4. Ability to deliver formal speeches/presentations & 1.14 & .351 & 1.56 & .527 \\
5. Ability to communicate orally with peers in small group discussion, & 1.75 & .732 & 1.56 & .527 \\
collaborative project, or out of class study group & & & & \\
6. Ability to communicate orally with teachers in or out of class & 1.53 & .609 & 1.56 & .726 \\
7. Interviewing or being interviewed & 1.78 & .866 & 2.00 & .707 \\
8. Requesting or receiving information in person & 2.06 & .893 & 2.22 & .667 \\
9. Classroom discussion on issue or situation & 1.75 & .806 & 1.78 & .833 \\
10. Formal speaking and responding as part of an audience & 1.61 & .599 & 1.89 & .601 \\
11.Conducting or participating in a meeting & 1.64 & .762 & 2.00 & .707 \\
12. Presenting or listening to oral reports or seminars & 1.69 & .710 & 1.56 & .726 \\
\hline
\end{tabular}

\section{Discussion}

The main aim of this study was to investigate oral communication needs of teachers and students as most important and most needed to enhance oral communication ability. The researcher began the discussion by answering the following research questions:

1). What are some of the oral communication abilities perceived important by the teachers and students?

The findings from the students' and teachers' questionnaire showed that oral communication abilities such as general listening comprehension, requesting or receiving information in person, lecture note taking, interviewing or being interviewed, and conducting or participating in the meeting were important oral communication ability by the teachers. Likewise, the five most important oral communication abilities in Section II were socializing with friends (e.g. organizing parties / picnics, telephone conversations, traveling in an English-speaking country 
(for example, taking a taxi, eating in restaurants), talking to foreigners and tourists who have visited foreign countries (e.g. giving instructions), participating in formal interviews and class discussions on current events and social problems were perceived as an important component of the students' oral communication skills. In addition, the five most important oral communication task from Section III were to enhance oral communication ability by the students are the receiving or requesting of information in person or by telephone, interviews or being interviewed, discuss a problem or situation, able to communicate successfully with friends in small group discussions, collective projects or study groups outside the classroom, and taking notes.

2). Which oral communications abilities are consider more significant by each group of participants compare to other group?

Table 4 shows that the students perceived oral communication skills such as requesting or receiving information in person or by telephone as most important followed by interviewing or being interviewed, while teachers rated the general comprehension of listening as the most important ability followed by requesting or receiving information in person or by telephone as an important component of oral communication abilities.

In summary, the results of the questionnaire suggested that teachers and students perceive speaking and listening informally in situations such as teamwork, small group discussion, role play, classroom interviews, informal debates, storytelling and ability to communicate with teachers as the most important oral communication abilities in English. Although it is important to use academic language in the classroom, daily conversation in English should also be taken into account to ensure effective communication in the classroom. The results of the questionnaire of teachers and students can be grouped into different oral linguistic processes and oral language activities such as;

- Narrating -storytelling, choral reading, reader's theatre, conversation in classroom,

- Describing - conversation in classroom, classroom discussion

- Explaining or expounding -public talk, informal classroom debates

- Persuading -public talk, informal classroom debates

- Arguing and defending -informal classroom debates

- Reporting -oral reports or presentation

- Informing - conversation in the classroom, brainstorming, pair interviews

- Discussing -panels discussion, roundtables discussion, oral reports

- Instructing or directing - oral directions and instructions

- Presenting - roundtable discussions, role play, panels, announcements, introductions,

- Questioning - roundtable discussions, pair interviews, panels, formulating, asking and answering questions, conversations in the classroom, informal classroom debates

- Problem-solving - discussion panels, brainstorming,

- Conversing - roundtable discussions, classroom conversations, greetings,

- Entertaining -choral reading and speaking, storytelling, recitation, public talk, informal classroom debates

\section{Conclusion}

This study was conducted to provide an overview of Bhutanese students' needs, purposes, and problems of oral communication and to find out teachers' perceptions of students' oral communication needs in the classroom. The results of this study provided a basis for a wide range of content, plan and application of an oral communication program in English in Bhutan, and involve people like students, teachers, and course designers during the planning stages. Though the present research does not represent all Bhutanese students and lack generalization, the researcher believes that the sampling framework can provide a relatively good representation of the Bhutanese student. The results of this study can be used as guiding principle for the developing oral communication programs in English that could enhance oral communication ability of Bhutanese students. It is expected that the conclusion of the present investigation could be utilized by the administrator and educators to plan the language instruction policy to enhance learners oral communication ability and as well as their language proficiency. This study may also serve as a guidelines for teachers of English language who wish to improve their students' language ability in terms of oral communication. Notwithstanding the important results of this study, the results were still limited to the needs and objectives of the target participants and did not cover classroom observation and interview of the participants as a part of data collection instrument. Hereafter, this 
study recommends a comprehensive investigation of students' needs, wants, and desire to learn oral communication in English by using classroom interview and observation as a data collection techniques.

\section{References}

Bhutan Council for School Examinations and Assessment. (2013). A Study of Student Achievements in English Literacy and Mathematics Literacy at Grade X. Thimphu: Bhutan Council for School Examinations and Assessment

Brindley, G. (1989). The role of needs analysis in adult ESL program design. In P. K. Johnson, (Ed.), The second language curriculum (pp. 63-78). Cambridge: Cambridge University Press.

Brown, J. D. (1995). The elements of language curriculum. Boston: Newbury House.

Bygate, M. (1987). Speaking. Oxford: Oxford University Press.

CAPSD. (2006b). English Reading \& Literature: Class VII. Thimphu: Curriculum and Professional Support Division, Department of School Education, Ministry of Education, Royal Government of Bhutan.

CAPSD. (2006a). English Curriculum Guide for Teachers: Class VI. Thimphu: Department of School Education, Ministry of Education, Royal Government of Bhutan.

DDC (Ed.) (2002). Dzongkha-English Dictionary. Thimphu: Dzongkha Development Commission.

Fatihi, A. R. (2003). The role of needs analysis in ESL program design. South Asian Language Review, 13, $39-59$.

Ferris, D., \& Tagg, T. (1996b). Academic listening/speaking tasks of ESL students: Problems, suggestions, and implications. TESOL Quarterly, 30(2), 297-320. https://doi.org/10.2307/3588145

Iwai, T., Kondo, K., Lim, D. S. J., Ray, G. E., Shimizu, H., \& Brown, J. D. (1999). Japanese language needs analysis 1998-1999. Honolulu, HI: University of Hawai'i at Mānoa, Second Language Teaching \& Curriculum Center.

LaPrairie, M. (2014). A case study of English-medium education in Bhutan. (Unpublished doctoral dissertation). Institute of Education, University of London, England

Mackay, R. (1978). Identifying the nature of the learner's needs. In R. Mackay, \& A. Mount ford (eds.), English for specific purposes (pp. 21-42). London: Longman.

Manolopoulou-Sergi, E. (2004). Needs analysis. In C. Ayakli, K. Karavas, E. Manolopoulou- Sergi, \& J. A. Spinthourakis (Eds.), Course design and evaluation: Introduction to the key concepts. Vol.1. (pp. 81-124). Patras: Hellenic Open University Nation, I.S.P and Macalister J. Language Curriculum Design, ESL \& Applied Linguistics Professional Series.

Richards, J. C. (2012). Curriculum development in language teaching. Cambridge: Cambridge Language Education.

Tarone, E., \& Yule, G. (1989). Focus on the language learner. Oxford: Oxford University Press.

Watanabe, Y. (2006). A needs analysis for a Japanese high school EFL general education curriculum. Second Language Studies, 25, 83-163.

Wu, G., \& Liang, J. (2007). Analysis of psychological barriers in oral English teaching. US-China Foreign Language, 5(9), 53-57.

\section{Copyrights}

Copyright for this article is retained by the author(s), with first publication rights granted to the journal.

This is an open-access article distributed under the terms and conditions of the Creative Commons Attribution license (http://creativecommons.org/licenses/by/4.0/). 